\title{
Low- versus high-concentration intravenous immunoglobulin for children with Kawasaki disease in the acute phase
}

\section{Takanori Suzuki}

Fujita Health University: Fujita Ika Daigaku

Nobuaki Michihata ( $\nabla$ michihata@m.u-tokyo.ac.jp)

The University of Tokyo: Tokyo Daigaku https://orcid.org/0000-0003-3091-114X

\section{Tetsushi Yoshikawa}

Fujita Health University: Fujita Ika Daigaku

\section{Kazuyoshi Saito}

Fujita Health University: Fujita Ika Daigaku

Hiroki Matsui

The University of Tokyo: Tokyo Daigaku

\section{Kiyohide Fushimi}

Tokyo Medical and Dental University: Tokyo Ika Shika Daigaku

\section{Hideo Yasunagaa}

The University of Tokyo: Tokyo Daigaku

\section{Research Article}

Keywords: Kawasaki disease, intravenous immunoglobulin, coronary artery abnormalities

Posted Date: September 2nd, 2021

DOI: https://doi.org/10.21203/rs.3.rs-859793/v1

License: (a) (i) This work is licensed under a Creative Commons Attribution 4.0 International License. Read Full License

Version of Record: A version of this preprint was published at International Journal of Rheumatic Diseases on March 8th, 2022. See the published version at https://doi.org/10.1111/1756-185X.14309. 


\section{Abstract}

Purpose: Few studies have compared the effects of low-concentration (5\%) and high-concentration (10\%) intravenous immunoglobulin (IVIG) preparations for patients with Kawasaki disease (KD) in the acute phase. The purpose of this study was to compare outcomes between low- and high-concentration IVIG preparations in children with KD, using a national inpatient database in Japan.

Method: We used the Diagnostic Procedure Combination database to identify patients with KD treated with IVIG from April 2012 to March 2020. We identified those receiving high- and low-concentration IVIG preparations as an initial treatment. The outcomes included the proportions of patients with coronary artery abnormalities (CAAs) and IVIG resistance, length of stay, and medical costs. Propensity scorematched analyses were conducted to compare the outcomes between the two groups. Instrumental variable analyses were performed to confirm the results.

Result: We identified 48,046 patients with KD and created 4:1 propensity score-matched pairs between the low- and high-concentration IVIG groups. There was a significant difference in the percentage with IVIG resistance between the two groups ( $20.6 \%$ vs $24.1 \%$; risk difference, $3.5 \%$ [95\% confidence interval, $2.3-4.7$ ]; $p<0.001)$. However, there was no significant difference in CAAs $(1.6 \%$ vs $1.6 \%$; risk difference, $0.013 \%$ [ $95 \%$ confidence interval, -0.34 to 0.37 ]; $p=0.953$ ). The instrumental variable analyses showed similar results.

Conclusions: The proportion of CAAs did not differ significantly between those receiving low- and highconcentration IVIG. To confirm the results of this study, prospective studies adjusting for duration of IVIG administration and duration of observation are needed.

\section{Background}

\section{What is Known:}

- For treatments of Kawasaki Disease in acute phase, intravenous immunoglobulin (IVIG) has been the most recommended to reduce fever early and prevent complications of coronary artery abnormalities. There are two types of IVIG preparations, low-concentration (5\%) IVIG and high-concentration (10\%) IVIG. However, few studies have performed comparisons to determine which preparation of IVIG is superior.

\section{What is New:}

- The present findings suggest that the proportion of coronary artery abnormalities did not differ significantly between those receiving low- and high-concentration IVIG.

\section{Introduction}

Kawasaki disease (KD), which is acute systemic vasculitis, is the most common cause of acquired heart disease in children in developed countries. ${ }^{1}$ Previously, $5 \%$ intravenous immunoglobulin (IVIG) preparations 
were used in Japan. Since January 2013, $10 \%$ IVIG preparations began to be used in Japan to treat patients with KD in the acute phase. In the United States, $10 \%$ IVIG preparations are already mainstream. Several previous studies have shown that halving the dose and duration of treatment for patients with KD in the acute phase may lead to earlier detection of IVIG resistance because of reduced volume load and shorter treatment duration. ${ }^{2-4}$ Additionally, more intense treatments can be used to suppress inflammation faster in patients with KD in the acute phase. No studies have evaluated the proportion of patients with IVIG resistance or coronary artery abnormalities (CAAs), length of stay, medical costs, or complications by different concentrations of IVIG. The purpose of this study was to compare the outcomes of children with KD treated with low-concentration (5\%) and high-concentration (10\%) IVIG preparations, using a national inpatient database in Japan.

\section{Methods}

\section{Data source}

For this retrospective cohort study, we used data derived from the Diagnosis Procedure Combination database. ${ }^{5}$ All 82 academic hospitals in Japan are obliged to participate in the database. Each year, data are collected on about eight million hospitalized patients of all ages, which is equivalent to about $50 \%$ of all acute-care hospitalizations in Japan. The database includes the following information: unique identifiers of hospitals; baseline patient characteristics; and diagnosis at admission, comorbidities at admission, and complications after admission recorded as text data in Japanese and using International Classification of Diseases, Tenth Revision (ICD-10) codes. The database also contains information on medical procedures and treatments (including drug administrations, device use, and surgical and nonsurgical procedures) based on the original Japanese codes; length of stay; discharge status; and medical costs during hospitalization. The attending physicians have to confirm the recorded patient data for all diagnoses and comorbidities with reference to medical records. Furthermore, because accurate reporting is linked with the payment system in Japan, the attending physicians and hospitals are required to accurately report diagnoses and comorbidities. The present study was approved by the Institutional Review Board of The University of Tokyo (approval number: 3501-(3); December 25, 2017). The requirement for informed consent was waived because of the anonymous nature of the data.

\section{Participants}

We used the database to identify patients who were diagnosed with KD (ICD-10 code: M303) from April 2012 to March 2020. We included patients whose first IVIG treatment was started within 3 days of hospitalization and who received at least $2 \mathrm{~g} / \mathrm{kg}$ of IVIG within 3 days of starting their initial IVIG treatment. We checked the Japanese text describing the detailed diagnoses in each case to include patients with atypical KD and exclude patients with "suspected" KD. We also excluded patients aged $>6$ years because the appropriate IVIG dose for older patients with KD remains controversial. We further excluded patients weighing $<3 \mathrm{~kg}$, those with missing data, and those with inadequate treatment $(<2 \mathrm{~g} / \mathrm{kg} \mathrm{IVIG})$. The included children with KD in the acute phase were divided into two groups depending on whether they had 
a $5 \%$ or $10 \%$ IVIG preparation as their initial treatment. We excluded patients who received both $5 \%$ and 10\% IVIG preparations.

\section{Outcomes}

The primary outcome was the occurrence of CAAs at the time of discharge. CAAs were identified using the recorded diagnosis of CAAs (ICD-10 code: I254) and/or the appearance of "CAAs" in the Japanese language text data. The secondary outcomes were the proportion of patients with IVIG resistance, length of stay, and medical costs. IVIG resistance was defined as the use of IVIG at a total dose of $\geq 4.0 \mathrm{~g} / \mathrm{kg}$ and/or in combination with any steroid, infliximab, cyclosporine, and/or plasma exchange that was not performed at the same time as the initial IVIG treatment. We also examined adverse events occurring with IVIG, including hyperviscosity syndrome (ICD-10 code: R70.1) and congestive heart failure (ICD-10 code: I50.0).

\section{Covariates}

The included baseline characteristics included sex, age, weight, height, hospital days of illness at initial IVIG, type of hospital, complex chronic conditions, ${ }^{6}$ activities of daily living at admission, Japan Coma Scale score at admission, transportation by ambulance, transportation from another hospital, fiscal year, additional treatments, and hospital volume. Assessments using the Japan Coma Scale have previously been shown to be highly correlated with assessments using the Glasgow Coma Scale. ${ }^{7}$ Hospital volume was defined as the annual number of all patients with KD at each hospital. We separated the included patients into hospital volume tertiles so that the numbers of patients in the groups were almost equal. Additional treatment was defined as the use of any steroid, infliximab, and/or cyclosporine at the same time as or before the start of the initial IVIG treatment.

\section{Propensity score-matched analysis}

We performed 4:1 propensity score-matched analyses to compare the outcomes between the two IVIG concentration groups. We estimated the propensity score using a logistic regression model in which $10 \%$ IVIG use was the dependent variable, with the covariates described above. For the propensity score matching, nearest-neighbor matching without replacement was performed. The caliper width was set at $\leq$ 0.2 of the pooled standard deviation of the evaluated propensity scores. We estimated the covariate balance between the two groups before and after propensity score matching using the absolute standardized difference. An absolute standardized difference of $>10 \%$ was regarded as imbalanced. ${ }^{8}$

Instrumental variable analysis

Propensity score-matched analyses cannot exclude the effects of unmeasured confounders such as symptoms of KD, laboratory data, duration of illness, duration of fever from KD onset, duration of IVIG administration, and duration of observation after initial IVIG treatment. Thus, to confirm our propensity score-matched analyses, we performed instrumental variable analyses. The key assumptions for instrumental variable analysis are as follows: the instrumental variable (i) is highly correlated with the 
treatment assignment, (ii) is not correlated with other confounders, and (iii) does not affect patient outcomes except through the treatment. ${ }^{9}$

In instrumental variable analyses, physician prescribing preference is commonly used as an instrumental variable. This variable reflects the notion that a physician's prescribing decision depends not only on the patient's characteristics but also on the physician's preference for each treatment. Physician's preference is mostly independent of patient characteristics and outcomes and can therefore be used as an instrumental variable. In the present study, we used prescription for previous patient as the instrumental variable. ${ }^{10}$ When the prescription for the previous patient in the same institution was $10 \%$ IVIG, the current patient was assumed to be more likely to receive $10 \%$ IVIG. When the prescription for the previous patient in the same institution was $5 \%$ IVIG, the current patient was assumed to be more likely to receive 5\% IVIG. Prescription for the previous patient is assumed to be independent of the current patient's characteristics and not directly related to their outcome. Therefore, this variable was considered to meet the three key requirements for an instrumental variable described above.

In this study, we employed a two-stage residual inclusion method for both continuous and binary outcome variables. ${ }^{11,12}$ In the first-stage model, we determined the row residual for each patient by calculating the difference between the model-predicted probability of receiving the treatment choice and the actual treatment received. These residuals were included as an additional covariate in the second-stage model, where the association between treatment choice and outcome was estimated in an unbiased manner after adjustment for covariates. We used a multivariable linear regression model for continuous outcome variables and a multivariable logistic regression model for binary outcome variables. All instrumental variable analyses were performed using robust standard errors. To assess the validity of the instrumental variable, we tested its association with our main predictor of actual treatment choice using the $F$-statistic ( $F$-statistic $>10$ is considered to reflect a valid instrumental variable) ${ }^{13}$ We also determined that the instrumental variable was not associated with the patient background characteristics or outcomes. A twosided $p<0.05$ was considered significant. All statistical analyses were conducted using Stata, version 17.0 (StataCorp LP, College Station, TX, USA).

\section{Statistical analysis}

Categorical variables, which are shown as numbers and percentages, were compared using Fisher's exact test. Continuous variables are shown as means and standard deviations or medians and interquartile ranges. The Mann-Whitney $U$ test was used to compare non-normally distributed variables between the two groups. Specifically, this test was used to compare length of stay and medical costs.

To allow for the meaningful interpretation of variables with skewed distributions, we calculated median differences with $95 \%$ confidence intervals $(95 \% \mathrm{Cls}$ ) using the Hodges-Lehmann estimator. The chi-square test was used to compare the proportions of patients with CAAs and IVIG resistance between the two groups. We also estimated the risk differences with $95 \%$ Cls. 
As a sensitivity analysis, CAAs were defined as a diagnosis of CAAs and the use of anticoagulants such as warfarin or clopidogrel, or a diagnosis of CAAs and cardiac catheterization. The diagnosis of CAAs was defined as the presence of a descriptive diagnosis of CAAs (ICD-10 code: 1254) or the use of "CAAs" to describe the case in the Japanese text data.

\section{Results}

Study population

We identified a total of 48,046 patients with KD who met the inclusion criteria, including 42,133 patients with $5 \%$ IVIG and 5913 patients with $10 \%$ IVIG as the initial treatment in the acute phase (Fig. 1). The baseline characteristics before and after propensity score matching are shown in Table 1. 
Table 1

Patient characteristics in the unmatched and propensity score-matched cohorts

\begin{tabular}{|c|c|c|c|c|c|c|}
\hline \multirow[t]{2}{*}{ Variable } & \multicolumn{3}{|c|}{ Unmatched patients } & \multicolumn{3}{|c|}{ Propensity score-matched patients } \\
\hline & $\begin{array}{l}\text { Low- } \\
\text { concentration } \\
\text { IVIG group }\end{array}$ & $\begin{array}{l}\text { High- } \\
\text { concentration } \\
\text { IVIG group }\end{array}$ & ASD & $\begin{array}{l}\text { Low- } \\
\text { concentration } \\
\text { IVIG group }\end{array}$ & $\begin{array}{l}\text { High- } \\
\text { concentration } \\
\text { IVIG group }\end{array}$ & ASD \\
\hline & $(N=42,133)$ & $(N=5913)$ & & $(N=23,636)$ & $(N=5909)$ & \\
\hline $\begin{array}{l}\text { Age (years), } \\
\text { mean (SD) }\end{array}$ & $1.9(1.6)$ & $2.1(1.7)$ & 9.5 & $2.0(1.7)$ & $2.1(1.7)$ & 0.4 \\
\hline $\begin{array}{l}\text { Male sex, } n \\
(\%)\end{array}$ & $23,839(56.6)$ & 3411 (57.7) & 2.2 & $13,713(58.0)$ & $3409(57.7)$ & 0.7 \\
\hline $\begin{array}{l}\text { Weight }(\mathrm{kg}) \text {, } \\
\text { mean (SD) }\end{array}$ & $11.7(3.6)$ & $12.1(3.8)$ & 10.7 & $12.0(3.7)$ & $12.1(3.8)$ & 0.4 \\
\hline $\begin{array}{l}\text { Height }(\mathrm{cm}) \\
\text { mean }(\mathrm{SD})\end{array}$ & $75.4(30.3)$ & $74.6(32.7)$ & 2.4 & $74.6(32.4)$ & $74.6(32.7)$ & 0.2 \\
\hline $\begin{array}{l}\text { Hospital days } \\
\text { of illness at } \\
\text { initial IVIG, } \\
\text { median (IQR) }\end{array}$ & $2.0(1.0-2.0)$ & $1.0(1.0-2.0)$ & 4.7 & $1.0(1.0-2.0)$ & $1.0(1.0-2.0)$ & 0.3 \\
\hline \multicolumn{7}{|l|}{$\begin{array}{l}\text { Type of } \\
\text { hospital, } n(\%)\end{array}$} \\
\hline $\begin{array}{l}\text { Academic } \\
\text { hospital }\end{array}$ & $7413(17.6)$ & $545(9.2)$ & 24.7 & $2068(8.7)$ & $545(9.2)$ & 1.7 \\
\hline \multicolumn{7}{|l|}{$\begin{array}{l}\text { Complex } \\
\text { chronic } \\
\text { conditions, } n \\
(\%)\end{array}$} \\
\hline $0-1$ & $40,554(96.3)$ & $5717(96.7)$ & 2.3 & $22,860(96.7)$ & $5713(96.7)$ & 0.2 \\
\hline$\geq 2$ & 1579 (3.7) & $196(3.3)$ & 2.3 & $776(3.3)$ & $196(3.3)$ & 0.2 \\
\hline $\begin{array}{l}\text { Transportation } \\
\text { by ambulance, } \\
n(\%)\end{array}$ & $936(2.2)$ & $159(2.7)$ & 3.0 & $597(2.5)$ & $159(2.7)$ & 1.0 \\
\hline $\begin{array}{l}\text { ADL at } \\
\text { admission, } \\
\text { mean (SD) }\end{array}$ & $80.7(36.0)$ & $81.9(34.8)$ & 3.3 & $82.1(34.5)$ & $81.9(34.8)$ & 0.8 \\
\hline $\begin{array}{l}\text { Japan Coma } \\
\text { Scale at } \\
\text { admission, } n \\
(\%)\end{array}$ & & & & & & \\
\hline
\end{tabular}

ADL, activities of daily living; ASD, absolute standardized difference; IQR, interquartile range; IVIG, intravenous immunoglobulin; SD, standard deviation 


\begin{tabular}{|c|c|c|c|c|c|c|}
\hline \multirow{2}{*}{$\begin{array}{l}\text { Variable } \\
0\end{array}$} & \multicolumn{3}{|c|}{ Unmatched patients } & \multicolumn{3}{|c|}{ Propensity score-matched patients } \\
\hline & 41,791 (99.2) & $5846(98.9)$ & 3.3 & $23,346(98.8)$ & $5842(98.9)$ & 0.9 \\
\hline 1 & $342(0.8)$ & $67(1.1)$ & 3.3 & $290(1.2)$ & $67(1.1)$ & 0.9 \\
\hline $\begin{array}{l}\text { Transported } \\
\text { from another } \\
\text { hospital, } n(\%)\end{array}$ & $32,063(76.1)$ & $4773(80.7)$ & 11.3 & $19,236(81.4)$ & $4773(80.8)$ & 1.6 \\
\hline \multicolumn{7}{|l|}{$\begin{array}{l}\text { Fiscal year, } n \\
(\%)\end{array}$} \\
\hline 2012 & $5332(12.7)$ & $1(0.0)$ & 53.7 & $4(0.0)$ & $1(0.0)$ & 0.0 \\
\hline 2013 & $5391(12.8)$ & $248(4.2)$ & 31.2 & $807(3.4)$ & $248(4.2)$ & 4.1 \\
\hline 2014 & $6037(14.3)$ & $341(5.8)$ & 28.8 & $1237(5.2)$ & $340(5.8)$ & 2.3 \\
\hline 2015 & $5219(12.4)$ & $432(7.3)$ & 17.1 & $1710(7.2)$ & $432(7.3)$ & 0.3 \\
\hline 2016 & $5365(12.7)$ & $616(10.4)$ & 7.3 & $2701(11.4)$ & $614(10.4)$ & 3.3 \\
\hline 2017 & $5428(12.9)$ & $821(13.9)$ & 3.0 & $3663(15.5)$ & $821(13.9)$ & 4.5 \\
\hline 2018 & $5442(12.9)$ & $1567(26.5)$ & 34.7 & $6270(26.5)$ & $1567(26.5)$ & 0.0 \\
\hline 2019 & 3919 (9.3) & 1887 (31.9) & 58.3 & $7244(30.6)$ & $1886(31.9)$ & 2.7 \\
\hline $\begin{array}{l}\text { Additional } \\
\text { treatment, } n \\
(\%)\end{array}$ & 4901 (11.6) & 721 (12.2) & 1.7 & 2811 (11.9) & $721(12.2)$ & 0.9 \\
\hline \multicolumn{7}{|l|}{$\begin{array}{l}\text { Hospital } \\
\text { volume, } n(\%)\end{array}$} \\
\hline Low (1-18.1) & $14,410(34.2)$ & $1453(24.6)$ & 21.2 & $5744(24.3)$ & $1453(24.6)$ & 0.7 \\
\hline $\begin{array}{l}\text { Middle (18.1- } \\
33.9)\end{array}$ & $14,154(33.6)$ & $1817(30.7)$ & 6.1 & 7432 (31.4) & $1817(30.7)$ & 1.5 \\
\hline High $(\geq 34.0)$ & $13,569(32.2)$ & $2643(44.7)$ & 25.9 & $10,460(44.3)$ & $2639(44.7)$ & 0.8 \\
\hline
\end{tabular}

The average annual numbers of patients with KD in the low-, medium-, and high-volume hospitals were < $18.1,18.1-33.9$, and $\geq 34.0$, respectively.

For the unmatched patients, compared with the 10\% IVIG group, the 5\% IVIG group had lower age, lower body weight, and a lower proportion transported from another hospital. The four-to-one propensity scorematched group included 23,636 patients in the low-concentration IVIG group and 5909 patients in the highconcentration IVIG group (Table 1). The characteristics of the patients in the matched cohort were well balanced between the two IVIG concentration groups, indicated by absolute standardized differences $<10 \%$ 
for all covariates. The comparisons between the $5 \%$ IVIG group and $10 \%$ IVIG group after propensity score matching are shown in Table 2. There were no significant differences between the $5 \%$ and $10 \%$ IVIG groups in the proportion of patients with CAAs $(1.6 \%$ vs $1.6 \%$; risk difference, $0.013 \%$ [ $95 \% \mathrm{Cl},-0.34$ to 0.37$] ; p=$ 0.953 ) or median medical costs (USD 6205 vs USD 6190; median difference, USD 8.0 [ $95 \% \mathrm{Cl}-45.6$ to 61.5]; $p=0.763$ ). There were significant differences between the $5 \%$ and $10 \%$ IVIG groups in the proportion of patients with IVIG resistance $(20.6 \%$ vs $24.1 \%$; risk difference, $3.5 \%$ [95\% $\mathrm{Cl}, 2.3-4.7] ; p<0.001)$ and median length of stay (9 days vs 9 days; median difference, 0 days [ $95 \% \mathrm{Cl}, 0-0] ; p<0.001$ ).

Table 2

Propensity score-matched analyses of outcomes in the high-concentration IVIG group versus the lowconcentration IVIG group among patients with Kawasaki disease

\begin{tabular}{|c|c|c|c|c|}
\hline & Propensity score-m & ned patients & Effect estimate* & $p$ \\
\hline & $\begin{array}{l}\text { Low-concentration } \\
\text { IVIG group }\end{array}$ & $\begin{array}{l}\text { High-concentration } \\
\text { IVIG group }\end{array}$ & & \\
\hline & $(N=23,636)$ & $(N=5909)$ & & \\
\hline $\begin{array}{l}\text { Percentage with CAAs } \\
(\%)\end{array}$ & 1.6 & 1.6 & $\begin{array}{l}0.013(-0.34 \text { to } \\
0.37)\end{array}$ & 0.953 \\
\hline $\begin{array}{l}\text { Percentage with IVIG } \\
\text { resistance (\%) }\end{array}$ & 20.6 & 24.1 & 3.5 (2.3 to 4.7$)$ & $\begin{array}{l}< \\
0.001\end{array}$ \\
\hline $\begin{array}{l}\text { Length of stay (days), } \\
\text { median (IQR) }\end{array}$ & $9(7-12)$ & $9(7-11)$ & 0 (0 to 0$)$ & $\hat{0}_{0.001}$ \\
\hline $\begin{array}{l}\text { Medical costs (USD), } \\
\text { median (IQR) }\end{array}$ & $6205(5200-7565)$ & $6190(5110-7785)$ & $\begin{array}{l}8.0(-45.6 \text { to } \\
61.5)\end{array}$ & 0.763 \\
\hline $\begin{array}{l}\text { CAAs, coronary artery } \\
\text { immunoglobulin; USD }\end{array}$ & $\begin{array}{l}\text { malities; } \mathrm{Cl} \text {, confider } \\
\text { d States dollars }\end{array}$ & nterval; IQR, interq & range; IVIG, intra & hous \\
\hline
\end{tabular}

The results of the instrumental variable analyses were similar to the results of the propensity scorematched analyses. IVIG concentration ( $10 \%$ vs $5 \%$ IVIG preparation) was not significantly associated with the proportion of patients with CAAs (odds ratio, 0.90 [95\% Cl, 0.66-1.22]) or medical costs (risk difference, USD -32.2 [ $95 \% \mathrm{Cl},-115$ to 50.6$]$ ). Compared with $5 \%$ IVIG, the IVIG concentration of $10 \%$ was significantly associated with a higher proportion IVIG resistance (odds ratio, 1.20 [95\% Cl, 1.09-1.33]) and shorter length of stay (risk difference, -0.57 days [ $95 \% \mathrm{Cl},-0.72$ to -0.43$]$ ) (Table 3). The F-statistic was $10,140(>10)$, and the instrument was considered valid. There was no significant association between the instrument and patient background (Supplemental Table). 
Table 3

Instrumental variable analyses of outcomes in the high-concentration IVIG group versus the lowconcentration IVIG group among patients with Kawasaki disease

\begin{tabular}{|llll|}
\hline & Odds ratio or coefficient & $\mathbf{9 5 \%}$ Cl & $p$ value \\
\hline Percentage with CAAs (\%) & 0.90 & 0.66 to 1.22 & 0.504 \\
\hline Percentage with IVIG resistance (\%) & 1.20 & 1.09 to 1.33 & $<0.001$ \\
\hline Length of stay (days) & -0.57 & -0.72 to -0.43 & $<0.001$ \\
\hline Medical costs (USD) & -32.2 & -115 to 50.6 & 0.446 \\
\hline CAAs, coronary artery abnormalities; Cl, confidence interval; IVIG, intravenous immunoglobulin; USD, \\
\hline United States dollars
\end{tabular}

Regarding the adverse effects of IVIG, none of the patients were diagnosed with hyperviscosity syndrome. Before propensity score matching, 24 patients in the $5 \%$ IVIG group and 5 in the $10 \%$ IVIG group had congestive heart failure. After propensity score matching, there was no significant difference in the proportions of patients with congestive heart failure between the two groups (risk difference, $0.042 \%$ [95\% $\mathrm{Cl},-0.04$ to 0.12$] ; p=0.199)$.

In the sensitivity analysis, there was a significant difference in the proportion of patients with CAAs in the propensity score analysis $(0.31 \%$ vs $0.61 \%$; risk difference, $0.30 \%$ [ $95 \% \mathrm{Cl}, 0.09-0.5] ; p=0.002)$. There was no significant difference in the proportion with CAAs in the instrumental variable analysis (odds ratio, 1.59 [95\% Cl, 0.93-2.72]).

\section{Discussion}

Using a large nationwide inpatient database in Japan, this study showed that the proportion with CAAs did not differ significantly between patients with KD receiving $5 \%$ and $10 \%$ IVIG in the acute phase. This result was similar in the propensity score analysis and the instrumental variable analysis.

Numerous studies have shown insignificant differences in outcomes between $5 \%$ and $10 \%$ IVIG for multifocal motor neuropathy, chronic inflammatory demyelinating polyradiculoneuropathy, primary immunodeficiency, and vesiculobullous autoimmune diseases. ${ }^{14-19}$ Previous small studies on KD have also shown no significant difference in the proportion with CAAs between $5 \%$ and $10 \%$ IVIG for patients with acute-phase $\mathrm{KD} .^{2,4}$

In this study, $10 \%$ IVIG was shown to increase the proportion of IVIG resistance in patients with acute KD. According to the 2012 Japanese KD guidelines, the observation period for KD is 24 hours after the completion of the first IVIG dose. ${ }^{20}$ In general, it is recommended that $5 \%$ IVIG should be administered to patients with KD within 24 hours of starting IVIG and that $10 \%$ IVIG should be administered to these patients within 12 hours of starting IVIG. IVIG resistance can therefore be determined at 36 hours from the 
start of dosing for the $10 \%$ IVIG formulation and at 48 hours from the start of dosing for the $5 \%$ formulation, after which IVIG can be re-administered.

The increased proportion of IVIG resistance with the use of $10 \%$ IVIG in this study may be explained by this difference in the observation period. In Japan, the 2020 KD guidelines basically recommend a decision whether a patient is IVIG resistance 48 hours after the start of IVIG administration. ${ }^{21}$ We believe that, in the future, as the new guidelines become more widespread and the follow-up period after IVIG lengthens, IVIG resistance resulting from the use of $10 \%$ IVIG may decrease.

In the propensity score analysis and the instrumental variable analysis, medical costs for the $10 \%$ IVIG group did not differ from those for the $5 \%$ IVIG group. A previous study showed that, in primary immunodeficiency, the widespread use of $10 \%$ IVIG has reduced medical costs and patient physical burden. ${ }^{17}$ If the proportion with IVIG resistance is modified according to the $2020 \mathrm{KD}$ guidelines, the use of $10 \%$ IVIG may help to shorten length of stay and reduce medical costs for patients with KD.

In the sensitivity analyses, different results were obtained for the proportion of patients with CAAs in the propensity score analysis and the instrumental variable analysis. The propensity analysis does not adjust for unmeasured confounding factors such as laboratory findings; if the 10\% IVIG group had more severe KD with poorer laboratory results compared with the $5 \%$ IVIG group, the $10 \%$ IVIG group may have had an excessively high proportion of patients with CAAs. It is also possible that the instrumental variable analysis did not meet the requirement of no relationship between unmeasured confounders and the instrumental variable. In fact, the results showed a relatively high number of patients receiving the $10 \%$ formulation in high-volume hospitals, and the proportion with CAAs may have tended to be lower in the $10 \%$ IVIG group than in the $5 \%$ IVIG group because high-volume hospitals are accustomed to treating KD. This suggests that the difference between the results from the propensity score analysis and the instrumental variable analysis may not be explained by differences in the IVIG concentration; rather, these differences may be explained by the severity of KD. Further detailed study is needed in the future.

\section{Limitations}

We acknowledge several limitations in this study. First, our database lacked information on KD symptoms, laboratory findings, and fever duration for patients with KD in the acute phase. The severity of KD was not identified clearly because bias still exists in the form of unmeasured confounders including laboratory findings, time from KD onset to hospital admission, and duration of illness. To adjust for differences in the severity of KD between the two groups, we used baseline characteristics including Japan Coma Scale score and complex chronic conditions to evaluate the propensity score-matched analyses. Furthermore, we performed instrumental variable analyses and obtained similar results to those from the propensity scorematched analyses. Second, information on the severity of the CAAs caused by KD, such as diameters and $Z$-scores, were not included in our database. To ensure that the CAAs were not transient, we added a sensitivity analysis using history of cardiac catheterization and prescription history of anticoagulants in addition to aspirin. Third, the accuracy of the times of IVIG administration, observation time, and the duration of fever among patients with KD could not be evaluated using the database. 


\section{Conclusions}

In this study, the proportion of patients with acute KD who had CAAs did not differ significantly between the $5 \%$ and $10 \%$ IVIG groups. To confirm the outcome observed in this study, prospective studies adjusting for duration of IVIG administration and duration of observation are required.

\section{Abbreviations}

ADL: activities of daily living; ASD: absolute standardized difference; CAAs: coronary artery abnormalities; $\mathrm{Cl}$ : confidence interval; IQR: interquartile range; IVIG: intravenous immunoglobulin; KD: Kawasaki disease; SD: standard deviation; USD: United States dollars

\section{Declarations}

Funding Source: This work was supported by grants from the Ministry of Health, Labour and Welfare, Japan (21AA2007 and 20AA2005) and the Ministry of Education, Culture, Sports, Science and Technology, Japan (20H03907).

Financial Disclosure: None of the authors have any financial relationships relevant to this article to disclose.

Conflict of Interest: None of the authors have any potential conflicts of interest to disclose.

Availability of data and material: Data cannot be made publicly available for ethical reasons as the data are patient data. The data are available to interested researchers upon request to the corresponding author, pending ethical approval.

Code availability: This study was analyzed using the standard packages of Stata software version 17.1 (StataCorp LP, College Station, TX, USA).

Authors' contributions: TS and NM conceptualized and designed the study, drafted the initial manuscript, and reviewed and revised the manuscript. TY, and KS conceptualized and designed the study, and coordinated and critically reviewed the manuscript for important intellectual content. HM, KF, and HY designed the data collection instruments, collected data, carried out the initial analyses, and reviewed and revised the manuscript. All authors approved the final manuscript as submitted and agree to be accountable for all aspects of the work.

Ethics approval, Consent to participate, Consent for publication: This article does not contain any studies with human participants or animals performed by any of the authors. Informed consent was waived because all data were de-identified. This study was approved by the Institutional Review Board of The University of Tokyo (approval number: 3501-(3) (December 25, 2017)).

\section{References}


1. Newburger JW, Takahashi M, Burns JC (2016) Kawasaki disease. J Am Coll Cardiol 67(14):17381749

2. Mima T, Ishizuka J, Higuchi Y (2020) Comparison of the safety and effectiveness of $5 \%$ immunoglobulin and $10 \%$ immunoglobulin for the treatment of Kawasaki disease. Pediatric Cardiology Cardiac Surgery 36(3):223-229

3. Ryuji F (2020) Usefulness of $10 \%$ immunoglobulin preparation. Pediatric Cardiology Cardiac Surgery 36(3):230-231

4. Oda $\mathrm{T}$, Nagata $\mathrm{H}$, Nakashima $\mathrm{Y}$ et al (2019) Clinical utility of highly purified $10 \%$ liquid intravenous immunoglobulin in Kawasaki disease. J Pediatr 214:227-230

5. Yasunaga H (2019) Real world data in Japan: chapter II the Diagnosis Procedure Combination database. Annals of Clinical Epidemiology 1(3):76-79

6. Simon TD, Berry J, Feudtner $C$ et al (2010) Children with complex chronic conditions in inpatient hospital settings in the United States. Pediatrics 126(4):647-655

7. Yumoto T, Naito H, Yorifuji T, Aokage T, Fujisaki N, Nakao A (2019) Association of Japan Coma Scale score on hospital arrival with in-hospital mortality among trauma patients. BMC Emerg Med 6(1):65 19 (

8. Austin PC, Stuart EA (2015) Moving towards best practice when using inverse probability of treatment weighting (IPTW) using the propensity score to estimate causal treatment effects in observational studies. Stat Med 34(28):3661-3679

9. Aso S, Yasunaga H (2020) Introduction to instrumental variable analysis. Annals of Clinical Epidemiology 2(3):69-74

10. Ionescu-Ittu R, Delaney JAC, Abrahamowicz M (2009) Bias-variance trade-off in pharmacoepidemiological studies using physician-preference-based instrumental variables: a simulation study. Pharmacoepidemiol Drug Saf 18(7):562-571

11. Terza JV, Basu A, Rathouz PJ (2008) Two-stage residual inclusion estimation: addressing endogeneity in health econometric modeling. J Health Econ 27(3):531-543

12. Terza JV, Bradford WD, Dismuke CE (2008) The use of linear instrumental variables methods in health services research and health economics: a cautionary note. Health Serv Res 43(3):1102-1120

13. Staiger D, Stock J (1997) Instrumental variables regression with weak instruments. Econometrica 65(3):557-586

14. Cats EA, van der Pol W-L, Piepers S, Notermans NC, van den Berg-Vos RM, van den Berg LH (2008) New liquid intravenous immunoglobulin $(10 \% \mathrm{IVIg})$ for treatment of multifocal motor neuropathy: a prospective study of efficacy, safety and tolerability. J Neurol 255(10):1598-1599

15. Wasserman RL, Melamed IR, Stein MR et al (2017) Evaluation of the safety, tolerability, and pharmacokinetics of Gammaplex ${ }^{\circledR} 10 \%$ versus Gammaplex ${ }^{\circledR} 5 \%$ in subjects with primary immunodeficiency. J Clin Immunol 37(3):301-310

16. Rappold LC, Denk K, Enk AH, Hadaschik EN (2016) Comparison of high-dose intravenous immunoglobulin (IVIG) in a 5\% and a 10\% solution does not reveal a significantly different spectrum 
of side-effects. J Eur Acad Dermatol Venereol 30(12):e186-e188

17. Kallenberg CGM (2007) A 10\% ready-to-use intravenous human immunoglobulin offers potential economic advantages over a lyophilized product in the treatment of primary immunodeficiency. Clin Exp Immunol 150(3):437-441

18. Alsina L, Mohr A, Montañés M et al (2017) Surveillance study on the tolerability and safety of Flebogamma ${ }^{\circledR}$ DIF (10\% and $5 \%$ intravenous immunoglobulin) in adult and pediatric patients. Pharmacol Res Perspect 5(5):e00345

19. Kuitwaard K, van den Berg LH, Vermeulen M et al (2010) Randomised controlled trial comparing two different intravenous immunoglobulins in chronic inflammatory demyelinating polyradiculoneuropathy. J Neurol Neurosurg Psychiatry 81(12):1374-1379

20. Saji T, Ayusawa M, Miura M, Kobayashi T (2012) The clinical guideline for medical treatment of acute stage Kawasaki disease. Pediatric Cardiology Cardiac Surgery 28:S1-S28

21. Miura M, Ayusawa M, Ito $S$. The guidelines on acute stage Kawasaki disease treatment. Pediatric Cardiology and Cardiac Surgery. 2020;36(S1):S1.1-S1.29

\section{Supplemental Table}

Supplemental Table. Patient characteristics and outcomes by the instrumental variable 
Low-concentration IVIG for previous patient $(N=41,483)$
High-concentration IVIG for previous patient $(N=5728)$
Age (years), mean (SD)

Male sex, $n(\%)$

Weight (kg), mean (SD)

Height (cm), mean (SD)

Hospital days of illness at initial IVIG, median (IQR)

Type of hospital, $n$ (\%)

Academic hospital

$7342(17.7)$

$2.0(1.0,2.0)$
$2.0(1.6)$ 3303 (57.7)

$11.8(3.7)$

73.7 (32.4)

$1.0(1.0,2.0)$

$511(8.9)$

Complex chronic conditions, $n(\%)$

\begin{tabular}{lll}
$0-1$ & $39,931(96.3)$ & $5538(96.7)$ \\
\hline$\geq 2$ & $1552(3.7)$ & $190(3.3)$ \\
\hline $\begin{array}{l}\text { Transportation by } \\
\text { ambulance, } n(\%)\end{array}$ & $932(2.2)$ & $142(2.5)$ \\
\hline $\begin{array}{l}\text { ADL at admission, mean } \\
(\text { SD })\end{array}$ & $80.8(36.0)$ & $81.6(35.1)$ \\
\hline
\end{tabular}

Japan Coma Scale at admission, $n(\%)$

\begin{tabular}{lll}
\hline 0 & $41,157(99.2)$ & $5664(98.9)$ \\
\hline 1 & $326(0.8)$ & $64(1.1)$ \\
\hline $\begin{array}{l}\text { Transported from another } \\
\text { hospital, } n(\%)\end{array}$ & $31,644(76.3)$ & $4625(80.7)$ \\
\hline Fiscal year, $n(\%)$ & \\
\hline 2012 & $4795(11.6)$ & $1(<1)$ \\
\hline 2013 & $5343(12.9)$ & $221(3.9)$ \\
\hline 2014 & $5954(14.4)$ & $338(5.9)$ \\
\hline 2015 & $5199(12.5)$ & $419(7.3)$ \\
\hline 2016 & $5339(12.9)$ & $596(10.4)$ \\
2017 & $5444(13.1)$ & $793(13.8)$
\end{tabular}




\begin{tabular}{lll}
\hline 2018 & $5485(13.2)$ & $1486(25.9)$ \\
\hline 2019 & $3924(9.5)$ & $1874(32.7)$ \\
\hline Additional treatment, $n(\%)$ & $4830(11.6)$ & $709(12.4)$ \\
\hline Hospital volume, $n(\%)$ & & \\
\hline Low $(1-18.1)$ & $13,940(33.6)$ & $1329(23.2)$ \\
\hline Middle (18.1-33.9) & $14,033(33.8)$ & $1780(31.1)$ \\
\hline High $(\geq 34.0)$ & $13,510(32.6)$ & $2619(45.7)$ \\
\hline
\end{tabular}

$A D L$, activities of daily living; IQR, interquartile range; IVIG, intravenous immunoglobulin; SD, standard deviation

\section{Figures}

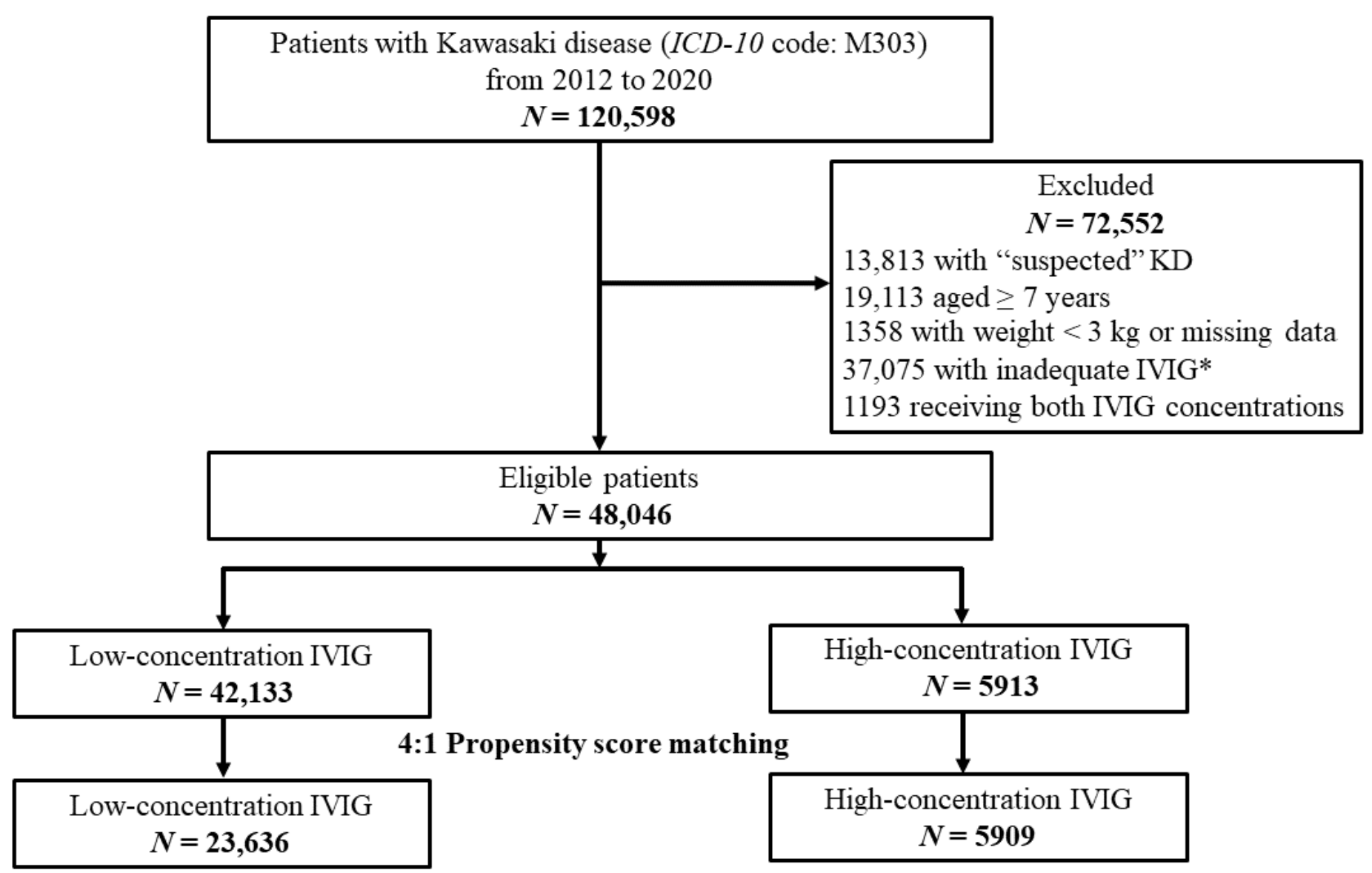

Figure 1 
Flow chart for the study cohort. IVIG, intravenous immunoglobulin. IVIG, intravenous immunoglobulin; KD, Kawasaki disease *Inadequate IVIG was defined as patients treated with $<2 \mathrm{~g} / \mathrm{kg}$ of IVIG during their initial treatment within 3 days of hospitalization. 